\title{
Lowering Preventable Maternal Deaths in Rural Georgia
}

\author{
Gabrielle Delimaํ, Amanda Engstrom², Emily Michels³, \\ Jay Qiu ${ }^{4}$ \\ 1Emory University School of Medicine, Department of Microbiology \& Immunology, Atlanta, GA \\ 2Emory University School of Medicine, Department of Cell Biology, Atlanta, GA \\ ${ }^{3}$ Emory University Laney Graduate School, Center for Ethics, Atlanta, GA \\ ${ }^{4}$ Emory University School of Medicine, Department of Human Genetics, Atlanta, GA \\ http://doi.org/10.38126/ISPG170205 \\ Corresponding author: Emily Michels emilylmichels@gmail.com \\ Keywords: maternal mortality; rural; Certified Nurse Midwives (CNM); tax credit; preventive care
}

\begin{abstract}
Executive Summary: Georgia's maternal mortality rate (MMR) is one of the highest in the U.S. and shows few signs of improvement, despite government intervention. Women living in rural areas are exposed to significantly higher risk than their urban counterparts and have reduced access to life-saving health care. $60 \%$ of Georgia's maternal deaths are preventable, however the lack of available providersespecially in rural areas-makes it hard to address these avoidable issues. As such, we propose an amendment to the Georgia legal code that would allow Certified Nurse Midwives (CNM) to practice independently, removing unnecessary restrictions on the low-risk and routine care that they are trained to provide. This change could lower systemic and individual health care costs while allowing an existing workforce to augment preventive care efforts.
\end{abstract}

\section{Georgia's ongoing maternal mortality crisis}

As most other developed countries have decreased their maternal mortality rates (MMR), the United States has seen an almost $60 \%$ increase from 2000 to 2017 (WHO et al. 2019). The Centers for Disease Control and Prevention (CDC) defines maternal mortality as "the death of a woman while pregnant or within 1 year of the end of a pregnancy...related to or aggravated by the pregnancy or its management" (CDC Division of Reproductive Health, NCCDPHP 2020). The U.S. 2018 MMR was 17.4 deaths per 100,000 live births - roughly 700 women per year (Hoyert and Miniño 2020), many of whose deaths were preventable (Georgia Department of Public Health 2019).

Georgia's MMR ranks amongst the highest in the country at 25.9 per 100,000 births, and continues to worsen (Georgia House Budget \& Research Office 2019), while states such as California, Massachusetts, and Nevada have the lowest rates at 4.0, 8.4, and 8.4 per 100,000 births, respectively (Unger and Simon 2018; "Maternal Mortality Rate..." 2020). Further, women in Georgia's rural counties-areas with a population less than 35,000 (Georgia State Office of Rural Health 2008) - are up to 50\% more likely to experience maternal mortality compared to women in urban areas (Georgia House Budget \& Research Office 2019). Access to care remains the central problem for women in rural Georgia. Of the 109 designated rural counties (by the State Office of Rural Health) 93 are without a hospital labor and delivery unit, and two-thirds of rural women are required to travel for delivery (Georgia House Budget \& Research Office 2019). 75 of the 109 rural counties are without an Obstetrician-Gynecologist (OB-GYN), and zero rural counties have a maternal-fetal specialist (Georgia House Budget \& Research Office 2019). Despite Georgia's attempts to curtail these rates and increase the rural workforce, the MMR has not improved. 


\section{Current response in Georgia}

Georgia has attempted to address the issue with little success reflected in yearly MMR. A study committee, the Maternal Mortality Review Committee (MMRC), as well as new reporting requirements for pregnancy-related deaths, have been implemented. Results of MMRC data collection have identified leading causes of death and major contributing factors, such as lack of access to care and little recognition or treatment of early warning signs. The committee also states that $60 \%$ of the maternal death cases they examined were preventable (Georgia Department of Health 2019). Each year recommendations are reported to decrease MMR through various actions such as early intervention, maternity education, and community involvement (Georgia Department of Health 2019).

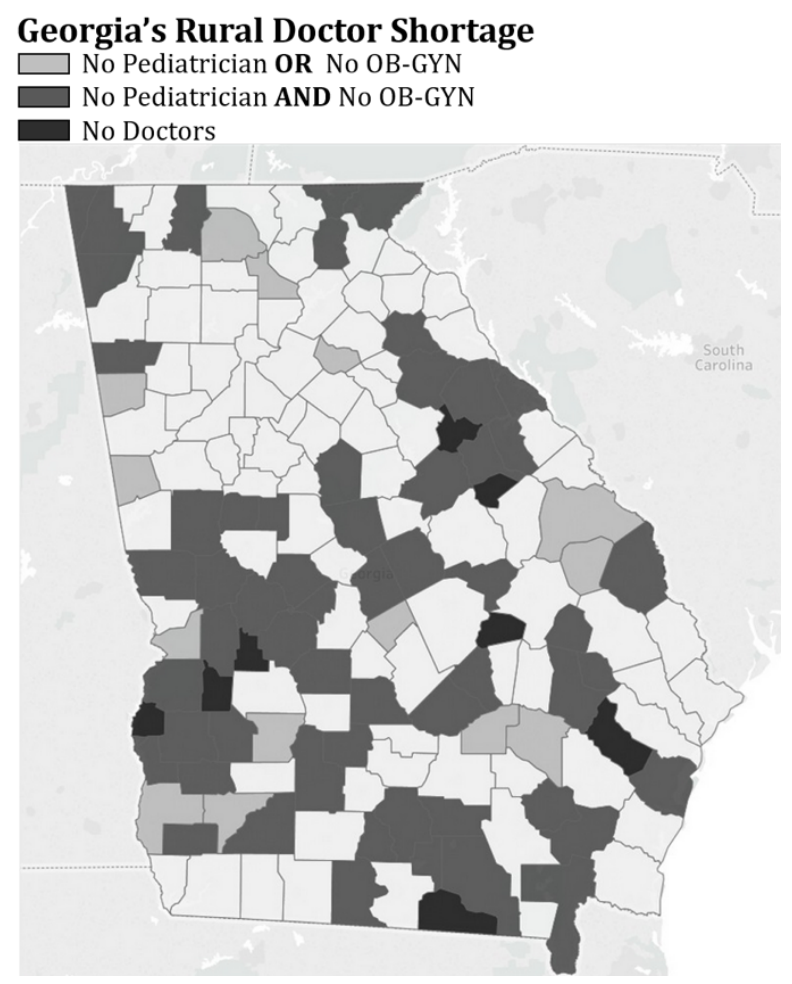

Figure adapted from Hart 2018

Financial approaches have also been attempted, such as the Rural Preceptor Tax Credit, which grants physicians a maximum $\$ 1,000$ in tax credits to mentor new providers (Laff 2016), and servicecancelable partial loan repayment for physicians, physician assistants, and advanced practice registered nurses (APRN) in underserved rural counties ("Loan Repayment Programs" 2020). Funding has been allotted for the improvement of rural birthing hospitals ( $\$ 2$ million), additional OB-
GYN residency slots ( $\$ 1.6$ million), and Medicaid reimbursement for rural prenatal care programs $(\$ 500,000)$ (Boockholdt 2019). Patient-focused approaches have also been proposed, such as pending House Bill 800, which allows rural Medicaid recipients in border counties to seek covered out-ofstate OB-GYN treatment within 50 miles of Georgia's border (Scott 2020).

Georgia's efforts are not reaching the in-need areas to the extent that the problem demands. Current incentive programs do not guarantee long-term physician service in rural areas, and women are still dying at alarming rates. We believe that creative solutions can be found within Georgia's existing workforce and infrastructure.

In this memorandum, we discuss two options: 1) expanding the scope-of-practice (SOP) for Certified Nurse Midwives (CNM) in Georgia and 2) expanding on rural incentive programs. In addition, we discuss the consequences of only relying on current policies.

\section{Policy options}

\section{i. Option 1: Amend Georgia code to increase CNM SOP to allow for independent practice.}

Georgia is among the most restrictive for Certified Nurse Midwives-providers who are licensed as APRNs and trained to incorporate physical, mental, and psychosocial factors into patients' treatmentrequiring a written agreement between a physician and up to four CNMs that outlines nurses' overall prescriptive and practice authority, including which of their responsibilities require physician supervision or approval ("States That Allow CNMs..." 2020). CNMs have master's degree level training in midwifery and their scope of practice includes not only labor and delivery and neonatal care, but many primary and gynecological care functions such as annual exams, chronic disease management, and family planning services (Ferreira 2020). CNM care is associated with reduced rates of cesarean sections, decreases in preterm births, and empowerment of expectant mothers to actively participate in their own care. It is important to note that prescriptive authority is only given to CNMs in states that allow for independent practice, of which Georgia is not one (Nursing@Georgetown 2019). 
We propose the amendment of GA Code §43-34-25 (2018 GA Code 2020) to eliminate the requirement for written protocols between physicians and APRNs. Independent practice encourages collaborative care instead of restrictive supervisory contracts and allows CNMs to utilize the full potential of their training and education. While physicians would still be responsible for highly complicated cases, CNMs would be able to manage low-risk and routine maternal care independently-including delivery assistance and monitoring of mother and babywithout superfluous physician supervision. 25 states currently allow for CNM independent practice, including states with some of the lowest MMR in the country ("States That Allow CNMs..." 2020).

\section{Advantages}

This amendment would allow CNMs to practice to a fuller potential, lessening the burden of care for physicians who must remain available for complicated cases. This change would no longer tie the number of available physicians to the number of CNMs able to practice and would minimize workforce disruption if supervising physicians leave rural areas. States with independent practice laws draw more CNMs on average than those with more restrictive laws (Yang, Attanasio, and Kozhimannil 2016). Studies demonstrate that states with fewer nurse practitioner (NP) restrictions "tend to exhibit an increase in the number and growth of NPs, greater care provision...and expanded health care utilization, especially among rural and vulnerable populations" (Xue et al. 2016).

Full SOP for APRNs can lower health care costs within the system and promote innovation (Adams and Markowitz 2018). Additionally, CNM care of low-risk women results in lower patient costs and more efficient resource use (Altman et al. 2017). This amendment would increase access to care for patients by utilizing the already-present and qualified workforce, decreasing the pressure to recruit new providers.

\section{Disadvantages}

This amendment would not change the requirement for physician involvement in complicated cases and does not negate the need for continued recruitment of both CNMs and physicians in rural areas. Independent practice shifts some of the responsibility from physicians to CNMs, which may result in an increased workload and longer hours for these providers, which, if imposed on a small population of providers, could be burdensome. One study demonstrates that nurse practitioners (NPs) in states with full prescriptive authority worked four percent more hours per year on average than those with restrictions, with no subsequent reduction to hours worked by physicians (Kleiner et al. 2016). Independent practice and the associated increase in workload and liability may also inspire calls for higher pay for CNMs (Spetz et al. 2018, 108), which could place financial strain on some rural hospitals and clinics.

ii. Option 2: Amend Georgia code to increase and extend rural physicians' tax credits.

Current Georgia regulation allows qualifying rural physicians-including OB-GYNs-to claim an additional tax credit of up to $\$ 5,000$ per year for up to five years (2010 Georgia Code 2020). Considering that $46 \%$ of rural residents are dependent on government healthcare, which reimburses services at lower rates, these tax credits help sustain medical practices that serve rural communities (National Advisory Committee on Rural Health and Human Services 2018; Barnett and Berchick 2017; Hart 2018). Extending this credit for an additional five years and increasing the credit to $\$ 10,000$ for each of those additional years would further incentivize OBGYNs to continue practicing and living in these communities (Gluck 2018).

We propose the amendment of GA Code $§ 48-7-29$ to extend tax credits for rural physicians from five to ten years and increase the credit to $\$ 10,000$ for years six through ten.

\section{Advantages}

The proposed amendment would aid efforts to recruit and retain OB-GYNs in rural communities by offering a financial incentive to maintain practices in these areas of need. Physicians who participate in incentive programs are more likely to remain in rural and underserved communities. In Nebraska, the median length of retention for rural family medicine providers was 4.3 years longer with incentive programs compared to those without (Pedley 2018). Additionally, bipartisan support is attainable, as there is no requirement for an expansion of Medicaid benefits. 


\section{Disadvantages}

Available data demonstrate that financial incentives are effective for short-term recruitment but, alone, may not translate into long-term retention. Other factors such as working conditions, job satisfaction, access to professional development and support are important determinants of long-term retention of practitioners (Pedley 2018; Gluck 2018; Misfeldt 2013). This amendment may prolong the presence of OB-GYNs in rural communities but does not guarantee the practices would remain once incentives cease. Moreover, additional tax credits would decrease annual tax revenue, complicating state budget planning.

\section{Consequences of inaction}

The majority of maternal-related deaths are within the poorest and most rural regions of Georgia. Current efforts in Georgia have attempted to address the high MMR by increasing the surveillance of MMR, creating additional OB-GYN residency programs, and a tax credit for rural physicians of up to $\$ 5,000$ per year for up to five years. Unfortunately, these actions fall short because, either they do not directly target

References

2010 Georgia Code. 2020. "O.C.G.A. 48-7-29 (2010)." Justia Law. Accessed April 2. https://law.justia.com/codes/georgia/2010/title -48/chapter-7/article-2/48-7-29/.

2018 Georgia Code. 2020. "GA Code § 43-34-25 (2018)." Justia Law. Accessed April 2. https://law.justia.com/codes/georgia/2018/title -43/chapter-34/article-2/section-43-34-25/.

Adams, E. Kathleen, and Sara Markowitz. 2018. "Improving Efficiency in the Health-Care System: Removing Anticompetitive Barriers for Advanced Practice Registered Nurses and Physician Assistants." Brookings, June, 1-32. https://www.brookings.edu/wpcontent/uploads/2018/06/AM_Web_20190122. pdf.

Altman, Molly R., Sean M. Murphy, Cynthia E. Fitzgerald, H. Frank Andersen, and Kenn B. Daratha. 2017. "The Cost of Nurse-Midwifery Care: Use of Interventions, Resources, and Associated Costs in the Hospital Setting." Women's Health Issues 27 (4): 434-40. doi:10.1016/j.whi.2017.01.002.

Barnett, Jessica C., and Edward R. Berchick. 2017. "Health Insurance Coverage in the United States: 2016." Census.gov Publications. The United States Census Bureau. September 17. https://www.census.gov/library/publications/2 017/demo/p60-260.html. rural Georgia or do not reach to the extent needed to create long-lasting change in the workforce of maternal healthcare providers in rural Georgia. Without legislation that is specifically designed to address the MMR issue in rural Georgia, access to routine maternal health care will continue to remain a significant barrier for mothers who are in most need. Inaction will leave Georgia to continue to have one of the highest MMR in the United States.

\section{Policy recommendation}

We recommend Option 1, to amend GA Code §43-3425 to allow CNM independent practice for routine and low-risk care. This amendment to the Georgia Code would increase the availability of health care providers statewide and would help reduce patient financial burden. A majority of the country, including states like Utah and North Dakota, has approved independent practice, yet Southern states-many of which rank poorly in terms of maternal mortalityare not represented. Georgia has the opportunity to be a leader in the South, expanding CNMs' SOP and working toward a better, healthier environment for Georgia's mothers and babies.

Boockholdt, Tara. 2019. "Maternal Mortality in Georgia." Georgia House Budget \& Research Office. April. http://www.house.ga.gov/budget/Documents/2 019 Session/2019 Policy Brief Maternal_Mortali ty in Georgia.pdf.

CDC Division of Reproductive Health, and National Center for Chronic Disease Prevention and Health Promotion (NCCDPHP). 2020. "Pregnancy Mortality Surveillance System." Reproductive Health. Centers for Disease Control and Prevention (CDC). February 4. https://www.cdc.gov/reproductivehealth/mater nal-mortality/pregnancy-mortality-surveillancesystem.htm.

Ferreira, Heather. 2020. "The Role of the Midwife in Primary Care." Brattleboro OBGYN. Brattleboro Memorial Hospital. Accessed April 5. https://www.bmhvt.org/the-role-of-themidwife-in-primary-care/.

Georgia Department of Public Health. 2019. "Maternal Mortality." Women and Children. Georgia Department of Public Health. November 22. https://dph.georgia.gov/maternal-mortality. 
Georgia House Budget \& Research Office. 2019. "House of Representatives Study Committee on Maternal Mortality." State of Georgia House of Representatives. State of Georgia. http://www.house.ga.gov/Documents/Committe eDocuments/2019/MaternalMortality/HR_589_F inal_Report.pdf.

Georgia State Office of Rural Health. 2008. "Georgia's Rural Counties." Georgia Department of Community Health.

August.

https://dch.georgia.gov/documents/georgiarural-county-map.

Gluck, Michael E. 2018. "Rapid Evidence Review: What Are Effective Approaches for Recruiting and Retaining Rural Primary Care Health Professionals?" Translation and Dissemination Institute. Academy Health. January 23. https://www.academyhealth.org/publications/2 018-01/rapid-evidence-review-what-areeffective-approaches-recruiting-and-retaining.

Hart, Ariel. 2018. "Georgia Faces Rural Doctor Shortage." Politics. The Atlanta Journal-Constitution. August 17. https://www.ajc.com/news/state--regionalgovt--politics/georgia-faces-rural-doctorshortage/IqAwfs1SLiqCwVNronKScM/.

Hoyert, Donna L, and Arialdi M Miniño. 2020. "Maternal Mortality in the United States." National Vital $\begin{array}{llll}\text { Statistics Reports } 69 & \text { (2): 1-16. }\end{array}$ https://www.cdc.gov/nchs/data/nvsr/nvsr69/n vsr69 02-508.pdf.

Kleiner, Morris, Allison Marier, Kyoung Won Park, and Coady Wing. 2016. "Relaxing Occupational Licensing Requirements: Analyzing Wages and Prices for a Medical Service." Journal of Law and Economics 59 (2): 261-91. doi:10.1086/688093.

Laff, Michael. 2016. "Tax Incentives Aim to Attract Primary Care Preceptors." AAFP News. American Academy of Family Physicians. June 14. https://www.aafp.org/news/educationprofessionaldevelopment/20160614preceptorcredits.html.

"Loan Repayment Programs." 2020. Loan / Scholarship Information. Georgia Board of Health Care Workforce. Accessed April 1 https://healthcareworkforce.georgia.gov/loanrepayment-scholarship-programs/loanrepayment-programs.

“Maternal Mortality Rate By State 2020." 2020. World Population Review. https://worldpopulationreview.com/states/mat ernal-mortality-rate-by-state/.
Misfeldt, Renee, Jordana Linder, Jana Lait, Shelanne Hepp, Gail Armitage, Karen Jackson, and Esther Suter. 2013. "Incentives for Improving Human Resource Outcomes in Health Care: Overview of Reviews." Journal of Health Services Research \& Policy 19 (1): 52-61. doi:10.1177/1355819613505746

National Advisory Committee on Rural Health and Human Services. 2018. Health Resources and Services Administration.

https://www.hrsa.gov/sites/default/files/hrsa/a dvisory-committees/rural/publications/2018Rural-Health-Insurance-Market-Challenges.pdf.

Nursing@Georgetown. 2019. “How Does the Role of NurseMidwives Change from State to State?" Nursing@Georgetown Blog. Georgetown University School of Nursing \& Health Studies. February 5. https://online.nursing.georgetown.edu/blog/sco pe-of-practice-for-midwives/.

Pedley, Andrew J. 2018. "Analyzing the Impact of Incentive Programs on Retention of Family Practice Providers in Rural Nebraska." University of Nebraska-Lincoln Community and Regional Planning Program: Professional Projects, July. https://digitalcommons.unl.edu/arch crp_profpr oj/14/.

Scott, Sandra, "Able" Mable Thomas, Dar'shun Kendrick, Valencia Stovall Stovall, Erica Thomas, and Renitta Shannon. 2020. 2019-2020 Regular Session - HB 800 Medical Assistance; Health Care Services by Providers in Bordering States to Georgia Medicaid Recipients under Certain Conditions; Provide. Georgia House of Representatives. http://www.legis.ga.gov/Legislation/enUS/display/20192020/HB/800.

Spetz, Joanne, Lisel Blash, Matthew Jura, and Lela Chu. 2018. "2017 Survey of Nurse Practitioners and Certified Nurse Midwives." Philip R. Lee Institute for Health Policy Studies, University of California San Francisco, April, 1-133. https://healthforce.ucsf.edu/sites/healthforce.uc sf.edu/files/publication-pdf/survey2017npcnmfinal.pdf.

"States That Allow CNMs to Practice and Prescribe Independently vs Those That Require a Collaborative Agreement." 2020. State Regulations for CNMs. MidwifeSchooling.com. Accessed April 1.

https://www.midwifeschooling.com/independen t-practice-and-collaborative-agreement-states/.

Ungar, Laura, and Caroline Simon. 2018. "Which States Have the Worst Maternal Mortality?" 50 States. USA Today. November 1. https://www.usatoday.com/list/news/investigat ions/maternal-mortality-by-state/7b6a2a480b79-40c2-a44d-8111879a8336/. 
WHO, UNICEF, UNFPA, World Bank Group, and United Nations Population Division. 2019. "Trends in Maternal Mortality 2000 to 2017." World Health Organization. WHO. https://apps.who.int/iris/bitstream/handle/106 65/327596/WHO-RHR-19.23-eng.pdf?ua=1

Xue, Ying, Zhiqiu Ye, Carol Brewer, and Joanne Spetz. 2016. "Impact of State Nurse Practitioner Scope-ofPractice Regulation on Health Care Delivery: Systematic Review." Nursing Outlook 64 (1): 7185. doi:10.1016/i.outlook.2015.08.005.
Yang, Y. Tony, Laura B. Attanasio, and Katy B. Kozhimannil. 2016. "State Scope of Practice Laws, NurseMidwifery Workforce, and Childbirth Procedures and Outcomes." Womens Health Issues 26 (3): 262-67. doi:10.1016/j.whi.2016.02.003

Gabrielle Delima is a $4^{\text {th }}$ year graduate student in the Microbiology and Molecular Genetics program at Emory University. She uses reverse genetics to map genetic determinants underlying influenza A virus gene expression as it pertains to host adaptation. After earning her PhD, Gabrielle plans to pursue a career in science policy and outreach.

Amanda Engstrom just received her PhD in Biochemistry and Cell Biology from Emory University. Her research focused on the mechanism of neuronal cell death in Alzheimer's disease and other related dementias. She will continue her research as a post- doctoral fellow. In addition to scientific research, Amanda is interested in science policy, STEM outreach, and being part of innovative mechanisms to communicate science to general audiences.

Emily Michels operates as a liaison between science, tech, and policy, working to educate policymakers and companies on the importance of ethical and scientifically sound internal and external policies. After working as a health policy analyst in Colorado, she received her Masters of Bioethics from Emory University in May 2020 with focuses on the ethics of HIV genetic sequencing-based interventions, community engagement, and artificial intelligence in health care.

Jay Qiu is a genetic counseling student in the Emory Genetic Counseling Training Program. His research is focused on the public's opinion and understanding of the limitations of direct-to-consumer genetic testing. He has an active interest in science and health policy and is passionate about the implementation of genomic research into clinical practice.

\section{Acknowledgements}

The authors would like to acknowledge the Emory Science Advocacy Network (EScAN) at Emory University especially Alyssa Scott, Erin King, Julia de Amorim, and Emily Hill for their comments on this publication.

\section{Disclaimer}

The authors disclose that they have no conflict of interest in this form. 